\title{
EL MANEJO DE LA INFORMACIÓN PRIVILEGIADA Y LA RESPONSABILIDAD DE LOS FUNCIONARIOS PÚBLICOS Y JUNTAS DIRECTIVAS
}

\author{
FEDERICO MONTIEL CASTILLO \\ Sistema de Estudios de Posgrado, \\ Universidad Estatal a Distancia \\ fmontiel@uned.ac.cr
}

\section{RESUMEN}

Este Artículo versa sobre dimensionar Responsabilidad del Funcionario Público en la Ley General de la Administración Pública, así como la de los miembros de la Junta Directiva de una entidad Financiera. Así mismo se abordan los conceptos de dolo y culpa como ejes centrales de la responsabilidad subjetiva y la exoneración. Finalmente se esboza las normas relativas a la información privilegiada y el delito de divulgación de secretos contemplado en el Código Penal, así como las funciones de control y fiscalización de la Superintendencia General de Entidades Financieras (SUGEF).

PALABRAS CLAVES: FUNCIONARIO PÚBLICO, INFORMACIÓN PRIVILEGIADA, DIVULGACIÓN DE SECRETOS, JUNTA DIRECTIVA, DELITOS BURSÁTILES.

\section{ABSTRACT}

This article refers to the responsibilities of a publicemployee and the members of the board of a financial institution as stated in the General Law for Public Administration. It also reviews the concepts of prevarication and guilt as central to subjective responsibility and exculpation. Finally, this articles offers an outline of the norms related to the concepts of privileged information and the disclosure of secrets as referred to in the Penal Code, plus an analysis of the functions of the Superintendent of Financial Institutions (SUGEF).

KEYWORDS: PUBLIC OFFICIAL, INFORMATION, DISCLOSURE OF SECRETS, BOARD, CRIMES STOCK.

\section{INTRODUCCIÓN}

La regulación de los sistemas financieros modernos se hace cada día más necesaria dada la versatilidad del mercado económico tanto en el contexto nacional como en el internacional. El desenvolvimiento de la economía de Costa Rica está estrechamente relacionado con su regulación financiera, ya que tiene que cumplir con estándares internacionales referidos a transparencia, seguridad, confiablidad y seguridad.

El impacto en las tecnologías de la información lleva a replantear muchas formas en las que actualmente se llevan a cabo los procesos económicos. Sin embargo, este acelerado auge requiere que el cuerpo normativo responda con la misma agilidad ante las necesidades de los mercados financieros.

Igualmente que el ordenamiento jurídico necesita adaptarse mejor ante los cambios que se suscitan en la economía moderna, el derecho penal económico debe hacer frente a nuevas formas de comisión de delitos que pueden causar serias distorsiones dentro de un campo tan regulado como el financiero-bancario.

En este artículo se abordará el régimen general de responsabilidad del funcionario público en Costa Rica, así como del miembro de Junta Directiva de una entidad financiera, y con particular referencia a las regulaciones de la información catalogadas 
como "de primera mano" dentro de la Ley orgánica del Banco Central, el control y fiscalización de la Superintendencia General de Entidades Financieras (SUGEF) y su relación con el Código Penal en el apartado de los Delitos Bursátiles.

\section{REFERENCIA PREVIA}

La construcción del sistema de responsabilidad del funcionario público tiene su esencia en la Ley General de la Administración Pública. En este régimen de responsabilidad en los conceptos de dolo y culpa grave. El mismo ha sido desarrollado ampliamente en Costa Rica. En el Acta No 104 de la Comisión Permanente de Gobierno y Administración de 3 de abril de 1970, p.10, se señala:

El funcionario va a responder ante la administración y va a responder al particular. Nosotros hemos querido coger toda esa evolución lo que consideramos que es sano. El principio sano consiste en que el funcionario sepa que no obstante que es funcionario debe tener el mismo deber de prudencia o diligencia y respeto a los derechos ajenos que el ciudadano común. No hay razón para que se castigue con responsabilidad a un ciudadano común que le causa un daño a otro, y no se castigue con igual responsabilidad a un empleado público que imprudentemente, negligentemente le causa un daño a un particular. Todavía es más punible nos parece éste último porque se supone que por su condición ha de tener no solo una conducta más ejemplar sino más controlada. El término tal (sic), es que el que viola gravemente sus deberes del cargo en realidad comete una negligencia punible. Sin embargo hemos optado por emplear dos términos que en Costa Rica se han empleado siempre en el Código Civil y en muchos ordenamientos nuestros. El dolo o culpa grave, que significa efectivamente una culpa que ya está muy definida por los tribu- nales. Dependiendo de cada caso, es aquel caso (sic) en dónde o intencionalmente o corriéndose (sic)... (Procuraduría General de la Republica, Dictamen C-014-2008).

De lo enunciado en el acápite anterior, se esboza la necesidad que tuvieron los legisladores de crear un sistema de responsabilidad de la administración pública y sus funcionarios frente al administrado.

También confluyen principios rectores del Mercado de Valores que permean la actuación de los funcionarios que colaboran en él:

Principio de Protección al inversor.- Así al inversor se le protege para que siga invirtiendo en valores por que esta es la condición esencial para que produzcan los fenómenos de inversión e intermediación en dicho mercado de valores. A través de este principio se garantiza la estabilidad de las entidades financieras en protección de los inversionistas y en defensa del normal funcionamiento del mercado de valores. Particularmente el Derecho del mercado de valores responde al a necesidad de proteger los derechos del inversionista. Esta protección se justifica por el hecho de que el nivel de riesgo en el que incurre el público que entrega sus fondos a las entidades financieras puede alterarse bruscamente y sin aviso (Hernández, 2002, p. 53-54).

\section{METODOLOGÍA}

Para la realización de esta investigación, se utilizó una metodología descriptiva, que corresponde a un análisis descriptivo de las disposiciones contenidas en la Constitución Política, Ley Orgánica del Banco Central, Ley General de la Administración Pública y Código Penal. Asimismo, se apoya en conceptos doctrinarios sobre el debido proceso, la responsabilidad objetiva y la responsabilidad subjetiva. Igualmente se hará 
mención a la jurisprudencia de la Sala Cuarta Constitucional de la Corte Suprema de Justicia, así como la jurisprudencia administrativa de la Procuraduría General de la República.

\section{EL BANCO CENTRAL Y LA SUPERINTENDENCIA GENERAL DE ENTIDADES FINANCIERAS (SUGEF)}

El Banco Central de Costa Rica se crea por Ley 1130, del 28 de enero del 1950, en el contexto de nacionalización de la banca, y con la necesidad de ir estructurando un sistema financiero organizado.

La Ley de creación y sus consecutivas reformas le brindan competencias claras al Banco Central. Dentro de sus funciones más relevantes están: a) mantener el valor externo y la conversión de la moneda nacional y b) el manejo de la política monetaria y cambiaria. El dinamismo, la versatilidad y la complejidad del sistema financiero, ha conllevado con el pasar del tiempo a la adopción de una serie de normativa tendiente a regular y supervisar la actividad financiera en Costa Rica. En razón de ello, se ha construido un engranaje importante de instituciones a nivel descentralizado, y con capacidad máxima de desconcentración que tienen la competencia exclusiva, unas en su rol de agentes que participan directamente en el mercado financiero, y otras que se encargan de las labores de supervisión de los distintos operadores, así como de las actividades que son llevadas a cabo dentro de este sistema.

Artículo 1.- Sistema Bancario Nacional estará integrado por:1) El Banco Central de Costa Rica; 2) El Banco Nacional de Costa Rica; 3) El Banco de Costa Rica; 4) El Banco Anglo Costarricense; (Derogado) 5) El Banco Crédito Agrícola de Cartago; 6) Cualquier otro banco del Estado que en el futuro llegare a crearse; y 7) Los bancos comerciales privados, establecidos y administrados conforme con lo prescrito en el Título VI de esta Ley. El sistema se regirá por la presente ley, la Ley Orgánica del Banco Central de Costa Rica y las demás leyes aplicables, así como por los respectivos reglamentos.

El Artículo 2: Los bancos del Estado enumerados en el artículo anterior son instituciones autónomas de derecho público, con personería jurídica propia e independencia en materia de administración. Estarán sujetos a la ley en materia de gobierno y deberán actuar en estrecha colaboración con el Poder Ejecutivo, coordinando sus esfuerzos y actividades. Las decisiones sobre las funciones puestas bajo su competencia sólo podrán emanar de sus respectivas juntas directivas (Ley 1130, del 28 de enero del 1950).

De acuerdo con lo anterior, cada banco tendrá responsabilidad propia en la ejecución de sus funciones, lo cual impone a los miembros de la junta directiva la obligación de actuar conforme a su criterio en la dirección y administración del banco, dentro de las disposiciones de la Constitución, de las leyes y reglamentos pertinentes y de los principios de la técnica, así como la obligación de responder por su gestión, en forma total e ineludible de acuerdo con los artículos 27 y 28 de la ley 1130.

En la figura 1 se visualiza la organización actual del Banco Central de Costa Rica, sus distintas dependencias, así como las Superintendencias que tiene adscritas en grado máximo de desconcentración.

Resulta de vital importancia para el tratamiento del tema de la Intermediación Financiera, lo que explica Hernández (2002):

La actividad de intermediación financiera- la actividad de canalización de los excedentes monetarios de las unidades oferentes hacia los demandantes -, desempeñan una fun- 
ción de enorme trascendencia social consistente en la conciliación de las necesidades de las unidades excedentarias o prestadoras y las deficitarias o prestarías. Pero, para que esa actividad sea eficaz y efectiva, se exige como presupuesto para su desarrollo de forma empresarial organizada para así poder abordar un gran número de operaciones, pues sólo de esa forma podrán obtenerse las finalidades perseguidas por la intermediación financiera (Hernández, 2002,p. 16).

Es importante agregar, para efectos de concretar los alcances sobre la responsabilidad pública, indica Ortiz (1996):

No importa si acción u omisión, si acto jurídico u operación material, si para el fin de la función o para otro diverso, si en obser- vación de todos los trámites legales o con prescindencia de los mismos, siempre que el cargo sea la ocasión aunque no sea el motivo único, siempre que el desempeño público brinde el contacto o los medios sin los cuales éste hubiere sido imposible, el delito o cuasidelito es imputable al Estado como causa de su responsabilidad subsidiaria (Ortiz.1996, p. 218).

Dentro de la supervisión bancaria, la Ley Orgánica de la Banca Nacional agrega en su artículo 16 "Además de la fiscalización a que estarán sometidos los bancos del Estado, de conformidad con las disposiciones especiales de la Constitución, dichos bancos y los privados quedarán sujetos a la vigilancia y fiscalización permanentes...."

FIGURA 2

\section{ORGANIGRAMA DE LA SUPERINTENDENCIA GENERAL DE ENTIDADES FINANCIERAS (SETIEMBRE 2011)}

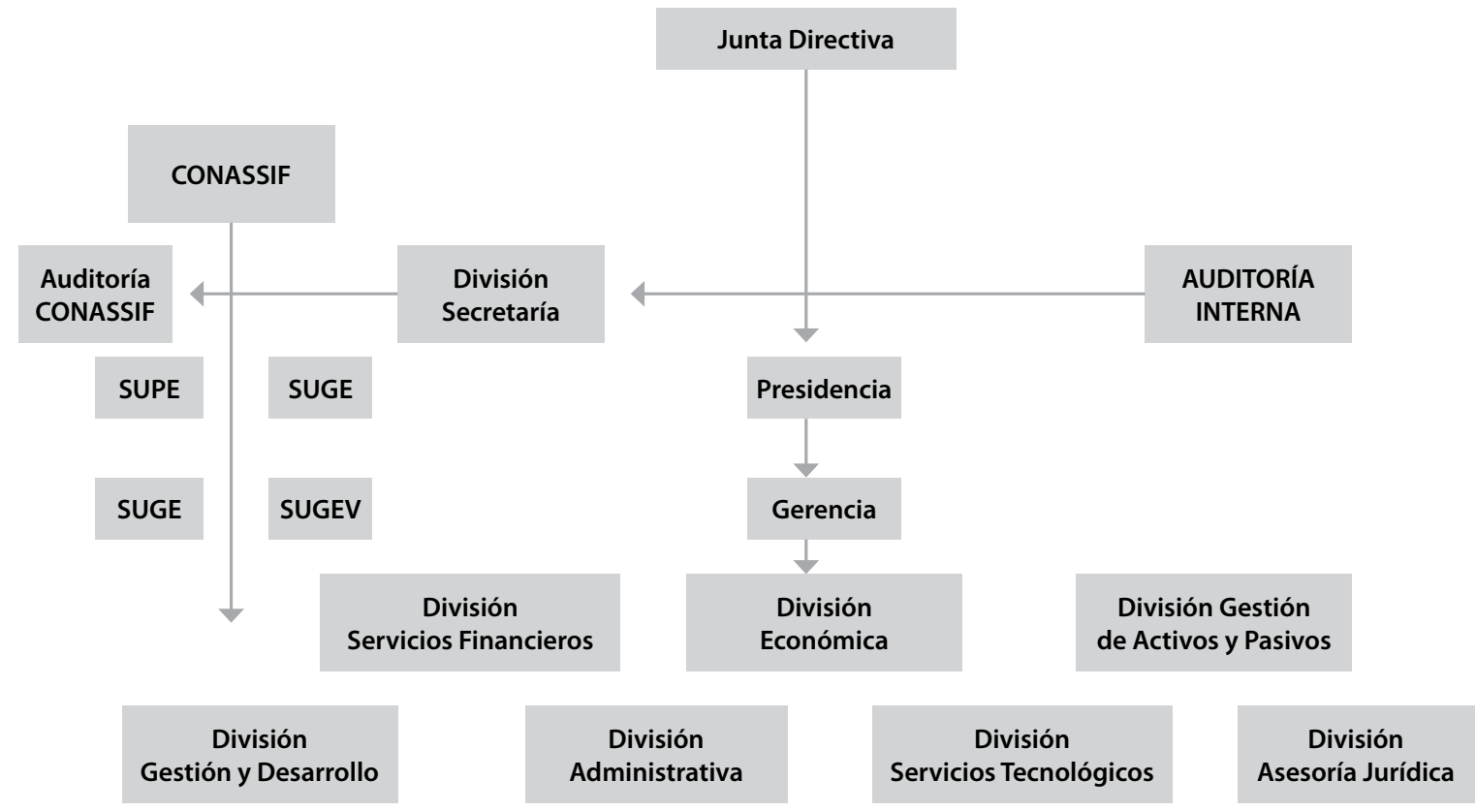

Fuente: Elaboración propia. 


\section{Creación y funciones de la Superintendencia General de Entidades Financieras (SUGEF)}

Por su parte, la Ley Orgánica del Banco Central, contempla la creación de la Superintendencia General de Entidades Financieras (SUGEF) en el artículo 115, dónde indica:

Creación. Es de interés público la fiscalización de las entidades financieras del país, para lo cual se crea la Superintendencia General de Entidades Financieras, también denominada en esta ley la Superintendencia, como órgano de desconcentración máxima del Banco Central de Costa Rica. La Superintendencia regirá sus actividades por lo dispuesto en esta ley, sus reglamentos y las demás leyes aplicables.

En la Figura 2 se explica la actual organización de la Superintendencia de Entidades Financieras, donde se muestran sus distintas dependencias que participan de las facultades que les confiere la Ley para la supervisión del mercando financiero.

De la norma comentada, primero que todo se declara de interés público la supervisión de todas las entidades financieras de país. Esto reviste de importancia, ya que el legislador ha determinado que para la comunidad o sociedad en general se hace necesario contar con dicha supervisión en las actividades financieras. Así mismo, se le concede a SUGEF un grado de desconcentración máxima dentro de la estructura del Banco Central de Costa Rica. Por lo tanto, y siguiendo la teoría de la desconcentración que estipula la Ley general de la Administración Pública la Junta Directiva del Banco Central puede dar lineamientos generales sobre la actividad del ente, más no determinar la forma de ejecutar el acto ( se gobierna la actividad, más no el acto ). Lo anterior se regula en el Artículo 99 de la Ley General de la Administración Pública que indica:
Artículo 99.- 1. Habrá relación de dirección cuando dos órganos de administración activa tengan diversa competencia por razón de la materia y uno de ellos pueda ordenar la actividad, pero no los actos, del otro, imponiéndole las metas de la misma y los tipos de medios que habrá de emplear para realizarlas, dentro de una relación de confianza incompatible con órdenes, instrucciones o circulares.2. La jerarquía implicará la potestad de dirección, pero no a la inversa.

Revisten de interés las siguientes disposiciones:

Artículo 118.- Control de la Superintendencia.- Los entes autorizados por el Banco Central a participar en el mercado cambiario, aun cuando no realicen intermediación financiera, quedarán sujetos a la supervisión de la Superintendencia. En este caso, la Superintendencia deberá vigilar que estos cumplan con las leyes y disposiciones del Banco Central en materia cambiaria.

Artículo 119.- Supervisión y fiscalización de la Superintendencia .- Con el propósito de velar por la estabilidad, la solidez y el eficiente funcionamiento del sistema financiero nacional, la Superintendencia ejercerá sus actividades de supervisión y fiscalización sobre todas las entidades que lleven a cabo intermediación financiera, con estricto apego a las disposiciones legales y reglamentarias, velando porque cumplan con los preceptos que les sean aplicables.....

Se denota de las normas supracitadas, que el legislador ha dado a la SUGEF las competencias necesarias para ejercer las labores de control, supervisión y fiscalización las cuales tienen que realizarse en estricto apego al ordenamiento jurídico, así mismo; le otorgó el poder de dictar la normativa que sea necesaria para dar lineamientos a las entidades supervisadas, las cuales serán de acatamiento obligatorio. 


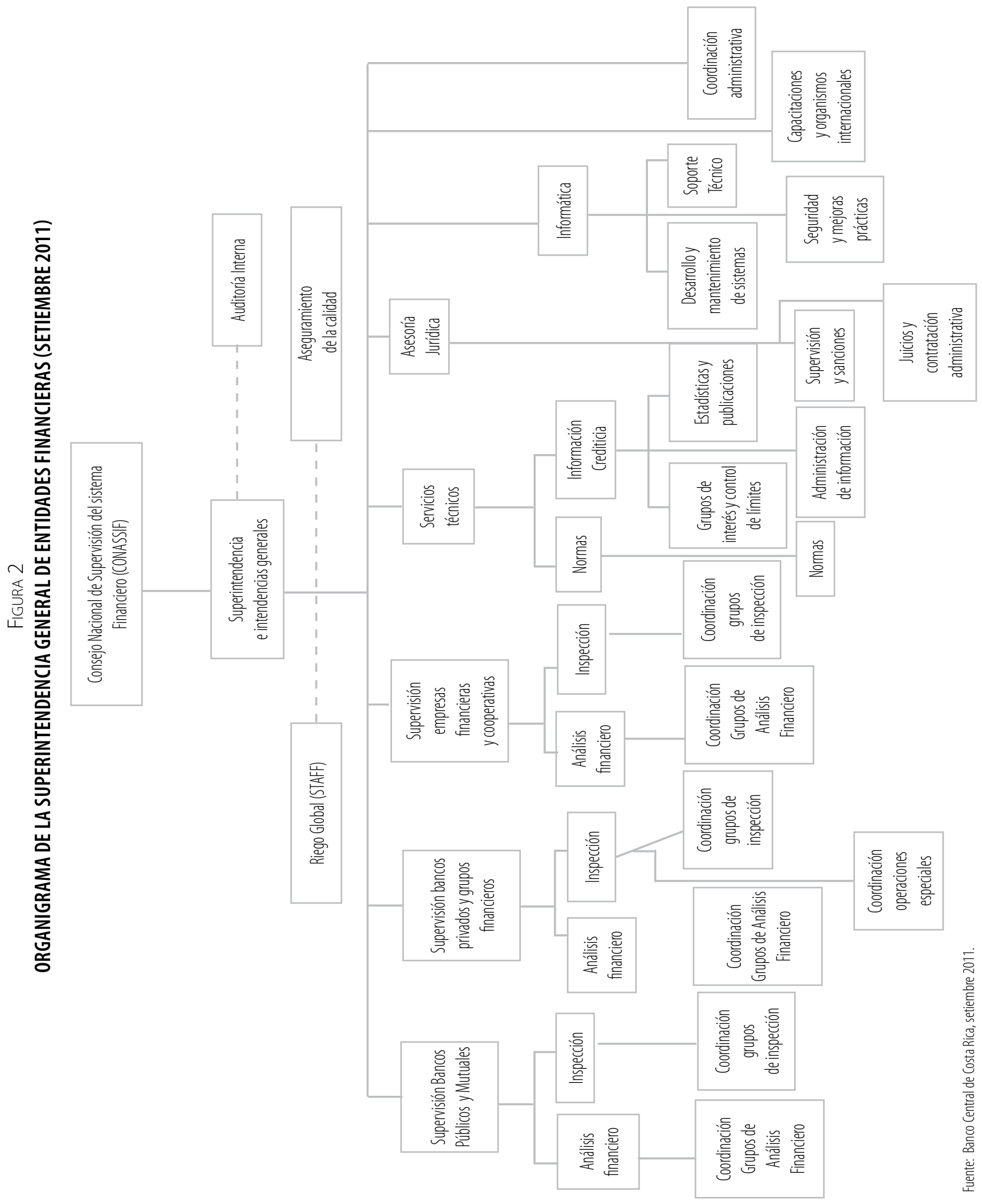




\section{Regulación de la información clasificada y la divulgación de secretos}

Ahora bien, y entrando propiamente en la materia del manejo de la información sea denominada "clasificada" o "sensible", dentro de las actividades que lleva a cabo la SUGEF, encontramos que el legislador ha restringido el manejo de la misma en el artículo 132:

Artículo 132.- Prohibición.- Queda prohibido al Superintendente, al Intendente, a los miembros del Consejo Directivo, a los empleados, asesores y a cualquier otra persona, física o jurídica, que preste servicios a la Superintendencia en la regularización o fiscalización de las entidades financieras, dar a conocer información relacionada con los documentos, informes $u$ operaciones de las entidades fiscalizadas. La violación de esta prohibición será sancionada según lo dispuesto en el artículo 203 del Código Penal. Tratándose de funcionarios de la Superintendencia constituirá, además, falta grave para efectos laborales.

Según la norma indicada, es prohibido dar a conocer a terceras personas información relativa a documentos, informes u operaciones de las entidades que están sujetas a fiscalización por parte de la SUGEF.

Igualmente, el Articulo 132 de la Ley Orgánica del Banco Central remite al artículo 203 del Código Penal, el cual en su versión actualizada dice:

Artículo 203.- Divulgación de secretos.-Será reprimido con prisión de un mes a un año o de treinta a cien días multa, el que teniendo noticias por razón de su estado, oficio, empleo, profesión o arte, de un secreto cuya divulgación pueda causar daño, lo releve sin justa causa. Si se tratare de un funcionario público o un profesional se impondrá, además inhabilitación para el ejercicio de cargos y oficios públicos, o de profesiones titulares, de seis meses a dos años.
Lo interesante de esta tipificación, es que se ubica en el Título Sexto denominado: "Delitos contra el ámbito de intimidad", Sección Primera: "Violación de Secretos". El legislador pudo concebir que el manejo de la información que se podría conocer por parte de las actividades de supervisión, control y fiscalización financiera esté circunscrita dentro del ámbito de la intimidad de la empresa o entidad supervisada. El señalar dicha información clasificada como "secreto", el incurrir en la conducta de su divulgación puede generar un daño a la organización financiera. Respecto al secreto bancario, el Código de Comercio de Costa Rica en su Artículo 615 indica: "Las Cuentas Corrientes bancarias son inviolables y los Bancos sólo podrán suministrar información sobre ellas a solicitud con autorización escrita del dueño, o por orden de autoridad competente". Se exceptúa la intervención que en cumplimiento de sus funciones determinadas por la ley haga la Auditoría General de Bancos. Queda prohibida la revisión de cuentas corrientes por las autoridades fiscales". Esta remisión por parte de la Ley Orgánica del Banco Central al artículo 203 del Código Penal, pareciera ser "curiosa", ya que los delitos que ahí se regulan están más relacionados con "secretos" relacionados con personas físicas, y no con personas jurídicas.

La actividad de fiscalización y supervisión financiera es de interés público, ejercida por una institución con grado de desconcentración máximo -como es la SUGEF-; quien tiene la competencia para determinar o clasificar la información brindada por la propia empresa o ente regulador o la propia superintendencia. En ese ejercicio, podría confundirse en la remisión de normas que se realiza entre La Ley Orgánica del Banco, el Código Penal y el Código de Comercio, por cuanto la información privilegiada, y el Delito de Divulgación de Secretos no pueden confundirse con el secreto bancario.

El Artículo 203 del Código Penal por su ubicación en los delitos contra la intimidad, puede generar confusión en primera instancia, más bien el cita- 
do artículo tenía que haber hecho referencia a información de carácter "confidencial", ya que el secreto bancario tiene otra connotación -como se dijo- ya que podría confundirse con el término genérico de "secreto". Asumiendo esta interpretación - en la cual secreto; entendido como el bancario, es sinónimo de información privilegiada- haría inoperante la actividad supervisora de la SUGEF, ya que constantemente tendría que requerir a un Juez de la República el levantamiento del secreto bancario para el cumplimiento de los fines que le ha encomendado el legislador.

Otras disposiciones importantes contenidas en el Código Penal son el Artículo 244:

Artículo 244: Manipulación de precios del mercado .-Será sancionado con pena de prisión de tres a ocho años, quien con el ánimo de obtener un beneficio para sí o para un tercero, o de perjudicar a otro participante del mercado, haga subir, bajar o mantener el precio de valores negociables en bolsa, mediante la afirmación o simulación de hechos o circunstancias falsas o la deformación u ocultamiento de hechos o circunstancias verdaderas, de modo que induzca a error sobre las características esenciales de la inversión o las emisiones.

De Igual forma se encuentra el Artículo 245:

Artículo 245. Uso de información privilegiada.- Será sancionado con pena de prisión de tres a ocho años quien conociendo información privilegiada relativa a los valores negociables en bolsa, sus emisores o relativa a los mercados de valores, adquiera o enajene, por sí o por medio de un tercero, valores de dichos emisores con el fin de obtener un beneficio indebido para sí o para un tercero. Para los efectos de este artículo, se considera como información privilegiada la que por su naturaleza puede influir en los precios de los valores emitidos y que aun no ha sido hecha del conocimiento público.
Aunado a lo anterior, y dado que el manejo de la información confidencial pudiera interpretarse tanto de las personas jurídicas y físicas que intervienen en el Mercado de Valores como una posible transgresión a su "derecho a la intimidad". Esto amerita un cierto "matiz" jurídico, ya que se podría confundir con el derecho constitucional a la "inviolabilidad de las comunicaciones" contenido en el Artículo 24 de la Constitución Política, norma fundamental que establece los alcances del mismo al indicar bajo cuales circunstancias concretas el legislador puede limitar el mismo, y cuales instituciones bajo sus facultades de control y fiscalización superior pueden tener acceso a la información cumpliendo con el debido proceso.

En la figura 3 se grafican los Delitos Bursátiles que contiene el Código Penal de Costa Rica:

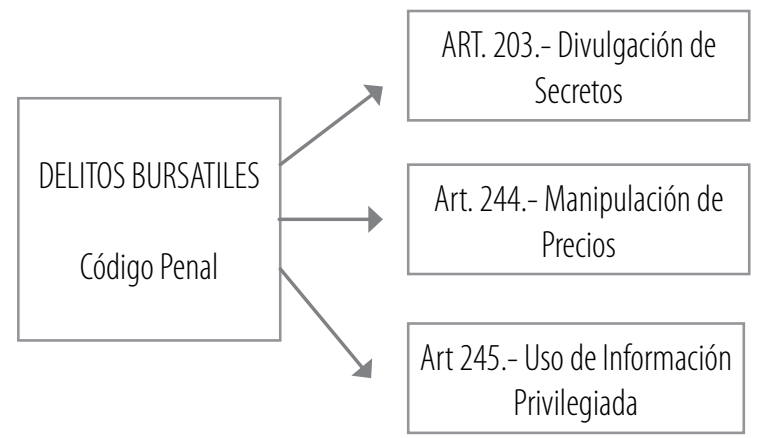

Fuente: Elaboración Propia.

\section{El Régimen de Responsabilidad para el Funcionario Público y para el miembro de Junta Directiva}

Es necesario invocar lo que dispone la Constitución Política de Costa Rica, la cual constituye el fundamento de la regulación tanto en el derecho administrativo, como en el penal dispone:

Artículo 39.- A nadie se le hará sufrir pena sino por delito, cuasidelito o falta, sancionados por ley anterior y en virtud de sentencia firme dictada por autoridad competente, previa oportunidad concedida al indiciado para ejercitar su defensa y mediante la necesaria demostración de culpabilidad. 
Sobre esta disposición constitucional se dice por la Doctrina Constitucional Costarricense:

Del principio de legalidad penal se puede derivar algunos principios importantes y que son de obligado acatamiento para los órganos administrativos del Estado en materia de potestad sancionatoria: a.- El primero de ellos se refiere específicamente a la legalidad de toda infracción administrativa, lo que implica, en principio, que toda potestad sancionatoria en el ámbito administrativo debe estar autorizada previamente por Ley. Sin embargo, existen matices importantes que deben ponerse de manifiesto. En efecto, la reserva legal en materia de sanciones administrativas, a diferencia del ámbito penal, no es absoluta sino relativa por varias razones: una está relacionada con el modelo constitucional de distribución de competencias, otra por el carácter insuprimible de la potestad reglamentaria en determinadas materias... (Hernández, 1998, p. 138).

Son importantes también, ciertas disposiciones normativas que contiene el Código Penal de Costa Rica: "Artículo 30.- No hay pena sin culpa.-Nadie puede ser sancionado por un hecho expresamente tipificado en la ley si no lo ha realizado con dolo, culpa o preterintención", también se agrega "Artículo 31.- Significado del dolo.-Obra con dolo quien quiere la realización del hecho tipificado, así como quien la acepta, previéndola a lo menos como posible". Por su parte, la Sala Tercera de la Corte Suprema de Justicia ha dicho en su jurisprudencia:

Culpa.-Culpabilidad. Es una garantía en tanto es la medida del reproche que corresponde realizar en forma individual a la persona concreta y específica que se pretende sancionar. Debe analizarse la capacidad de culpabilidad o imputabilidad, integrada a su vez por: 1. la capacidad de conocer el carecer ilícito del hecho y 2. La capacidad de adecuar la conducta a ese conocimiento. No fundamentar estos aspectos lesiona el derecho de defensa y el deber de expresar todas y cada una de las razones que determinan la condena del justiciable. N 317-20008 de las 10:10 horas del 18 de abril del 2008.

Para el caso del dolo se indica: "Dolo Prueba.- El contenido cognitivo y volitivo de la acción no tiene prueba directa, salvo casos de resolución manifestada. El dolo se infiere inductivamente del análisis de las circunstancias de modo, tiempo y lugar, conforme a la sana crítica. Considerando III. N 657-98de las 9:20 horas del 10 de julio de 1998".

En la figura 4 se esquematiza el régimen central de responsabilidad, donde se enuncian los conceptos de dolo y culpa, que concluyendo cualquiera de ambos a través de un proceso en sede administrativa o judicial, el funcionario se le impondrá la sanción correspondiente.

FIGURA 4

\section{RÉGIMEN CENTRAL DE RESPONSABILIDAD}
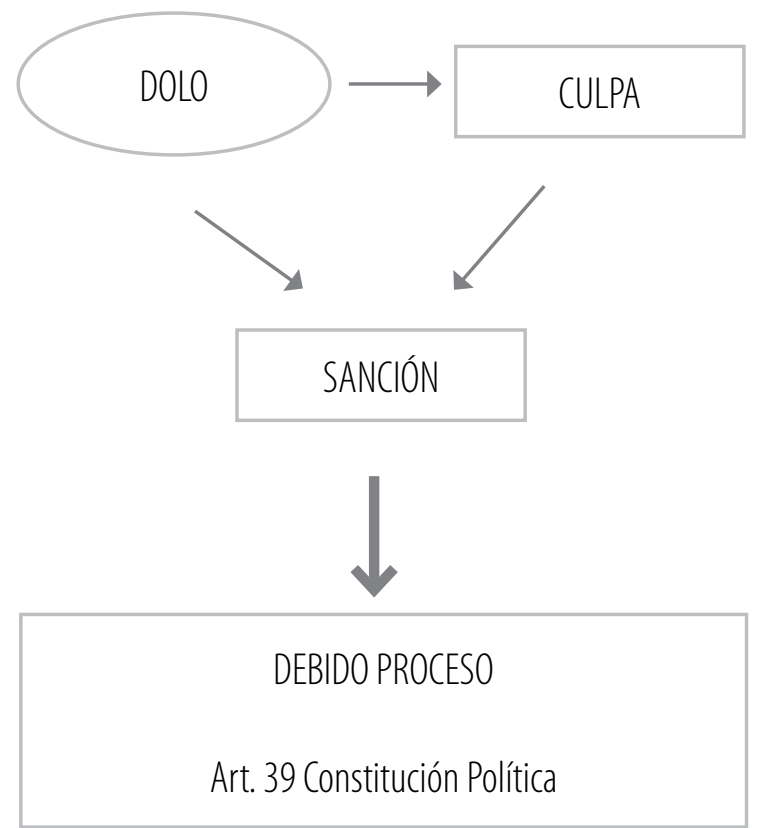

Fuente: Elaboración Propia. 


\section{La responsabilidad del funcionario público en Costa Rica}

En cuanto al tema de la responsabilidad del funcionario público, en primer lugar hay que comentar las disposiciones que contiene la Ley General de la Administración Pública: Artículo 199.- 1. Será responsable personalmente ante terceros el servidor público que haya actuado con dolo o culpa grave en el desempeño de sus deberes o con ocasión del mismo, aunque sólo haya utilizado los medios y oportunidades que le ofrece el cargo. (Lo subrayado no es del texto original). La norma citada, señala la responsabilidad del funcionario público en sede administrativa, civil, disciplinaria, se requiere que haya cometido la infracción con dolo o culpa grave. Esto es importante, porque al concepto tradicional de "culpa" anteriormente dicho, se agrega que para un funcionario público la misma debe ser "grave"; es decir, no se requiere cualquier falta al deber genérico de prudencia, diligencia o cuidado, sino que responderá solo ante las faltas graves en el ejercicio de su cargo. Sobre el principio de responsabilidad subjetiva del funcionario público, la Procuraduría General de la República en Opinión Jurídica OJ-005-2002 señala:

... en reiteradas ocasiones hemos indicado que a diferencia de la responsabilidad de la Administración, la responsabilidad del funcionario no es objetiva, sino subjetiva, de conformidad con la regulación que contiene la Ley General de la Administración Pública. Esto es así, porque el funcionario público responde personalmente frente a terceros o ante la propia Administración, cuando haya actuado con culpa grave o dolo (La diferencia entre ambos conceptos radica, según la doctrina, en la voluntariedad o intencionalidad de la acción u omisión; en razón de lo cual habrá dolo cuando exista deliberada voluntad de dañar, y culpa cuando medie negligencia o imprudencia), según lo disponen los artículos 188 y 210 de la citada Ley General.
En la Tabla 1 se sintetiza los Artículos de la Ley General de la Administración Pública que contienen las disposiciones atinentes a la responsabilidad del Funcionario Público, así como los distintos tipos de responsabilidad.

\section{TABLA 1 \\ DISTINTOS TIPOS DE RESPONSABILIDAD DEL FUNCIONARIO PÚBLICO}

\begin{tabular}{|c|c|}
\hline Tipo de Responsabilidad & $\begin{array}{l}\text { Ley General de la } \\
\text { Administración } \\
\text { Pública }\end{array}$ \\
\hline Ante Terceros & Art. 199 \\
\hline Solidaria & Art. 201 \\
\hline Recuperación de Pagado con Daños y Perjuicios. & Art. 202 y 203 \\
\hline Acción Ejecutiva de Cobro & Art. 204 \\
\hline Distribución del daño entre varios funcionarios & Art.205 \\
\hline Disciplinaria & Art. 211 \\
\hline $\begin{array}{l}\text { Por delegación, culpa grave en la vigilancia } 0 \\
\text { en la elección del delegado }\end{array}$ & Art. 212 \\
\hline Ante mayor jerarquía, mayor responsabilidad & Art. 213 \\
\hline
\end{tabular}

Fuente: Elaboración Propia

\section{RESPONSABILIDAD DE LOS MIEMBROS DE JUNTAS DIRECTIVAS}

El tema de la responsabilidad como miembro de una Junta Directiva de una entidad financiera, reviste de total trascendencia, ya que sus implicaciones pueden incidir directamente en la gestión de la entidad, así como en su imagen frente a los usuarios o potenciales clientes de dicha entidad.

En cuanto a la constitución de las Juntas Directivas, y su responsabilidad en el ejercicio de su cargo, la Ley Orgánica del Banco Central de Costa Rica puntúa:

Artículo 27. Cada Junta Directiva ejercerá sus funciones con absoluta independencia y bajo su exclusiva responsabilidad, dentro de las normas establecidas por las leyes, los reglamentos aplicables y los principios de la técnica. Los miembros de las juntas directivas ten- 
drán la más completa libertad para proceder, en el ejercicio de sus funciones, conforme con su conciencia y su propio criterio, por cuya razón serán personalmente responsables de su gestión en la dirección general del respectivo banco. Sobre ellos pesará cualquier responsabilidad que conforme con las leyes pueda atribuírseles por dolo, culpa o negligencia. Quienes no hubieren hecho constar su voto disidente, responderán personalmente con sus bienes de las pérdidas que le irroguen al banco, por la autorización de operaciones prohibidas por la ley, o que hayan sido autorizadas mediante dolo, culpa o negligencia. La asunción de algún margen de riesgo comercial no será un hecho generador de su responsabilidad personal, en tanto haya tenido adecuada proporción con la naturaleza de la operación emprendida, y no se haya actuado con dolo, culpa o negligencia; todo de conformidad con las reglas de la sana negociación bancaria..."

Agrega el artículo 28:

Artículo 28: Todo acto, resolución u omisión de una Junta Directiva que contravenga las disposiciones legales y reglamentarias o que signifique empleo de los fondos del banco en actividades distintas de las inherentes a sus funciones, hará incurrir a todos los presentes en la sesión respectiva en responsabilidad personal y solidaria para con el Banco, el Estado y terceros afectados, por los daños y perjuicios que con ello se produjeren. De tal responsabilidad quedarán exentos únicamente los asistentes que hubieren hecho constar su voto disidente o su objeción, en el acta de sesión correspondiente. Todo ello sin perjuicio de las otras sanciones legales que pudiera corresponderles.

Como se desprende del Artículo 27, la responsabilidad para los personeros de una Junta Directa de un Banco, se tipifica por la comisión de actos dolosos, culposos y/o negligentes. Aquí se denota la primer separación del régimen de responsabilidad que se comentó - el común- para los funcionarios públicos en los artículos 199 y 200 y siguientes de la Ley General de la Administración Pública; la razón obedece a que los miembros de dichos órganos colegiados no ostentan una relación laboral de empleo público típica, ya que los mismos tiene otro régimen de contratación laboral diferido, y por lo tanto, no son funcionarios de la entidad, no cumplen jornada horaria, tampoco se encuentran bajo la "subordinación" y no perciben un salario, sino el pago de una dieta; lo anterior implica que no se cumplen los requisitos para la existencia de un contrato de trabajo.

Del Artículo 28 transcrito, se estipula claramente la exclusión de la responsabilidad del miembro que integra una Junta Directiva: "De tal responsabilidad quedarán exentos únicamente los asistentes que hubieren hecho constar su voto disidente o su objeción, en el acta de sesión correspondiente".

El hecho de intervenir como una posición de garante en las funciones de supervisor del sistema financiero, aumenta la posibilidad de generar mayor imputación por responsabilidad objetiva a los miembros de la Junta Directiva, sea para el caso del Banco Central de Costa Rica: "Empero, de otro modo, si la supervisión y fiscalización de la intermediación financiera funciona mal o del todo no funciona ante supuestos en los que debe desplegar sus potestades-deberes, se crea una situación de riesgo que posibilita la propia Administración por su posición de garante, aunque se autor directo sea un sujeto privado. El Banco Central de Costa Rica -en este casodebe responder por que al incumplir su deber de garante da lugar a una lesión que podría haberse evitado o al menos paliado de haberse realizado la actividad exigida. Su funcionamiento anormal es pues, reflejo de su actuación negligente" (Ortiz, 2005, p. 93).

\section{CONCLUSIONES}

El Banco Central de Costa Rica, al igual que la Superintendencia General de Entidades Financieras ostentan un rol preponderante en la fisca- 
lización y supervisión del sistema financiero en el marco legal que les ha atribuido el legislador.

La regulación de las sanciones por el manejo de la información privilegiada encuentra su regulación tanto en la Ley Orgánica del Banco Central de Costa Rica, así como en el Código Penal que establece los delitos bursátiles.

Producto de esta investigación se concluye que la forma en que se ha estructurado y la remisión que hace la Ley Orgánica del Banco Central al Código Penal, genera una confusión al operador normativo, ya que se establece en la primera el concepto de información privilegiada, y en el Código Penal los delitos bursátiles se encuentran contenidos delitos contra la intimidad, no teniendo relación alguna su ubicación con la materia bursátil.

El Régimen de Responsabilidad del Funcionario Público encuentra su fundamento en el Artículo 39 de la Constitución Política, al preceptuar las garantías constitucionales del debido proceso para lograr la imposición de las sanciones por la comisión de un delito o infracción a la Ley. El Régimen genérico de Responsabilidad Subjetiva del Funcionario Público, se regula en los Artículos 199 y siguientes de la Ley general de la Administración Pública, en la cual los conceptos de dolo y culpa grave son el eje central.

La Responsabilidad para un miembro de una Junta Directiva de una entidad financiera se especializa del genérico que está establecido para los funcionarios públicos, ya que los Directores no tienen un contrato laboral típico con la entidad financiera.

La responsabilidad del Directivo de una entidad financiera será juzgada por la comisión de conductas dolosas o culposas según el Artículo 27 y 28 de la Ley Orgánica del Banco Central de Costa Rica, salvo que la conducta objeto de investigación tipifique en un delito más grave.

El Directivo de una entidad financiera debe hacer constar su voto negativo en el acta de discusión de la sesión respectiva, esto para exonerarse de responsabilidad por las atribuciones que le han sido conferidas para el ejercicio de su puesto.

\section{REFERENCIAS}

Asamblea Legislativa (1949). Constitución Política. Editorial Costa Rica: Costa Rica.

Asamblea Legislativa (1964). Código de Comercio. Editorial Costa Rica: Costa Rica.

Asamblea Legislativa (1970). Código Penal. Editorial Costa Rica: Costa Rica.

Asamblea Legislativa (1978). Ley General de la Administración Pública. Editorial Costa Rica: Costa Rica.

Asamblea Legislativa (1995). Ley Orgánica del Banco Central de Costa Rica. Editorial Costa Rica: Costa Rica.

Asamblea Legislativa (2008). Ley Reguladora del Mercado de Valores. Editorial Costa Rica: Costa Rica.

Hernández Aguilar Álvaro. (2002). Derecho Bursátil (Mercado de Valores), Tomo I, Investigaciones Jurídicas, S.A. San José .Costa Rica.

Hernández Valle Rubén. (1998) La Constitución Política de la República de Costa Rica, Comentada y Anotada. Primera Edición, San José, Juricentro.

Ortiz Ortiz Eduardo. (1996). Expropiaciones y Responsabilidad Pública. Litografía e Imprenta LIL. San José, Costa Rica.

Ortiz Zamora Luis A. (2005). La Responsabilidad in vigilando del Banco Central de Costa Rica por la Supervisión del Sistema Financiero Nacional. Instituto Iberoamericano de Derecho Administrativo

Poder Judicial, Sala Cuarta de la Corte Suprema de Justicia, Voto 1265-1995

Poder Judicial, Sala Cuarta de la Corte Suprema de Justicia, Voto 8193-2000.

Poder Judicial, Sala Tercera de la Corte Suprema de Justicia, Considerando III. N 657-98, de las 9:20 horas del 10 de julio de 1998

Poder Judicial, Sala Tercera de la Corte Suprema de Justicia, N³17-20008 de las 10:10 horas del 18 de abril del 2008.

Procuraduría General de la República en Dictamen C-3492008 del 25 de setiembre 2008

Procuraduría General de la República en Opinión Jurídica OJ-005-2002

Procuraduría General de la República ha mencionado en Dictamen C-044-2008 del 13 de Febrero del 2008.

Procuraduría General de la República, Dictamen C-132-89 de 27 de julio de 1989 